\title{
New Hepatitis C Therapies in Clinical Development
}

\author{
Johannes Vermehren and Christoph Sarrazin \\ Medizinische Klinik 1, Klinikum der J. W. Goethe-Universität, Frankfurt am Main, Germany
}

\begin{abstract}
With the current standard of care for the treatment of chronic hepatitis C, a combination of pegylated interferon alfa and ribavirin, sustained virologic response rates can be achieved in approximately $50 \%$ of patients only.

Improved understanding of the viral life cycle has led to the identification of numerous potential targets for novel, direct-acting antiviral compounds. Inhibitors of the NS3/4A protease are currently the most advanced in clinical development. Recently completed phase 3 studies of the two protease inhibitors telaprevir and boceprevir, each given in combination with standard of care, yielded sustained virologic response rates in the range of $66-75 \%$ in treatmentnaive patients and $59-66 \%$ in treatment-experienced patients with HCV genotype 1 infection. Studies of second-generation protease inhibitors, with the potential advantage of improved potency, drug metabolism and pharmacokinetics profile, are already underway.

Inhibitors of the HCV NS5A protein and NS5B polymerase are potentially active across different HCV genotypes and have shown promising antiviral efficacy in early clinical studies. Other emerging mechanisms include silymarin components and inhibitors of cell proteins required for HCV replication.

While improved formulations of current HCV therapies are also being developed, future hopes lie on the combination of direct-acting antivirals with the eventual possibility of interferon-free treatment regimens.
\end{abstract}

Key words: chronic hepatitis C; direct-acting antivirals; protease inhibitor; polymerase inhibitor; NS5A inhibitor; cyclophilin inhibitor.

\section{INTRODUCTION}

Chronic infection with the hepatitis $\mathrm{C}$ virus (HCV) affects more than $3 \%$ of the world's population [1]. There are about 4 million carriers in Europe alone who are at risk of developing advanced liver fibrosis, cirrhosis and hepatocellular carcinoma.

With the current standard of care (SOC; pegylated interferon [PEG-IFN] alfa and ribavirin [RBV]), only $40-50 \%$ of patients with HCV genotype 1 infection and about $80 \%$ of patients with HCV genotype 2 or 3 infection can be cured [2-5]. In addition, long treatment durations and therapy-associated side effects such as severe cytopenia, flu-like symptoms or depression are associated with treatment discontinuation in a significant number of patients.

Recent advances in the development of HCV cell culture systems and replication assays have improved our understanding of the viral life cycle, thus leading to the identification of numerous potential targets for novel HCV therapies [6-9]. Indeed, every step of the $\mathrm{HCV}$ life cycle may be used as a therapeutic target. However, direct-acting antivirals that target post-translational processing of the $\mathrm{HCV}$ polyprotein and inhibitors of the HCV replication complex are currently the most advanced in clinical development, with studies ranging from pre-clinical to phase 3 . Other promising therapeutic targets include cell proteins that are required for HCV replication such as cyclophilins. Finally, improvements of current therapies, such as new interferon and ribavirin formulations are also in active development.

In this review, we will give an overview of recent advances in HCV drug discoveries with a special emphasis on direct-acting antivirals that have progressed to phase 2-3 clinical development with anticipated higher cure rates and shorter treatment durations compared to standard therapy (Table 1). Approval of the first DAAs is expected by mid-2011.

\section{Antivirals targeting HCV Polyprotein PROCESSING}

\section{NS3/4A PROTEASE INHIBITORS}

The HCV NS3/4A protease has been recognized as an important target for antiviral therapy due to its key role within the HCV life cycle (e.g. cleavage of the genome-encoded polyprotein and inactivation of cellular proteins required for innate immunity) [6].

Inhibitors of the HCV NS3/4A serine protease are currently the furthest along in development and they have shown strong antiviral efficacy but a low genetic barrier to resistance in early clinical studies. Protease inhibitors can be divided into two chemical classes, macrocyclic inhibitors and linear, tetra-peptide $\alpha$-ketoamide derivates (Table 1 ).

The clinical proof-of-concept for NS3/4A protease inhibitors was achieved with ciluprevir (BILN 2061), a macrocyclic protease inhibitor that showed substantial antiviral activity in patients with HCV genotype 1 [10]. However, ciluprevir was not further developed due to serious cardiotoxicity observed in a monkey model. 
Table 1. New HCV therapies in the pipeline.

\begin{tabular}{|c|c|c|c|}
\hline Drug name & Company & Target / Active drug & Study phase \\
\hline \multicolumn{4}{|l|}{ NS3/4A protease inhibitors } \\
\hline Ciluprevir (BILN 2061) & Boehringer Ingelheim & Active site / macrocyclic & Stopped \\
\hline Boceprevir (SCH503034) & Merck & Active site / linear & Phase 3 \\
\hline Telaprevir (VX-950) & Vertex & Active site / linear & Phase 3 \\
\hline Danoprevir (RG7227) & Roche & Active site / macrocyclic & Phase 2 \\
\hline TMC435 & Tibotec / Medivir & Active site / macrocyclic & Phase 2 \\
\hline Vaniprevir (MK-7009) & Merck & Active site / macrocyclic & Phase 2 \\
\hline BI 201335 & Boehringer Ingelheim & Active site / linear & Phase 2 \\
\hline BMS-650032 & Bristol-Myers Squibb & Active site & Phase 2 \\
\hline GS-9256 & Gilead & Active site & Phase 2 \\
\hline ABT-450 & Abbott / Enanta & Active site & Phase 2 \\
\hline Narlaprevir (SCH900518) & Merck & Active site / linear & On hold \\
\hline PHX1766 & Phenomix & Active site & Phase 1 \\
\hline ACH-1625 & Achillion & Active site / linear & Phase 2 \\
\hline IDX320 & Idenix & Active site / macrocyclic & On hold \\
\hline MK-5172 & Merck & Active site / macrocyclic & Phase 1 \\
\hline VX-985 & Vertex & Active site & Phase 1 \\
\hline GS-9451 & Gilead & Active site & Phase 1 \\
\hline \multicolumn{4}{|c|}{ Nucleos(t)ide NS5B polymerase inhibitors } \\
\hline Valopicitabine (NM-283) & Idenix / Novartis & Active site / NM-107 & Stopped \\
\hline RG7128 & Roche / Pharmasset & Active site / PSI-6130 & Phase 2 \\
\hline IDX184 & Idenix & Active site & On hold \\
\hline R1626 & Roche & Active site / R1479 & Stopped \\
\hline PSI-7977 & Pharmasset & Active site & Phase 2 \\
\hline PSI-938 & Pharmasset & Active site & Phase 1 \\
\hline INX-189 & Inhibitex & Active site & Phase 1 \\
\hline \multicolumn{4}{|c|}{ Non-nucleoside NS5B polymerase inhibitors } \\
\hline BILB 1941 & Boehringer Ingelheim & NNI site 1 / thumb 1 & Stopped \\
\hline BI 207127 & Boehringer Ingelheim & NNI site 1 / thumb 1 & Phase 2 \\
\hline MK-3281 & Merck & NNI site 1 / thumb 1 & Stopped \\
\hline Filibuvir (PF-00868554) & Pfizer & NNI site $2 /$ thumb 2 & Phase 2 \\
\hline VX-916 & Vertex & NNI site 2 / thumb 2 & On hold \\
\hline VX-222 & Vertex & NNI site 2 / thumb 2 & Phase 2 \\
\hline VX-759 & Vertex & NNI site $2 /$ thumb 2 & Phase 1 \\
\hline ANA598 & Anadys & NNI site 3 / palm 1 & Phase 2 \\
\hline ABT-333 & Abbott & NNI site 3 / palm 1 & Phase 2 \\
\hline ABT-072 & Abbott & NNI site 3 / palm 1 & Phase 2 \\
\hline Nesbuvir (HCV-796) & ViroPharma / Wyeth & NNI site 4 / palm 2 & Stopped \\
\hline Tegobuvir (GS-9190) & Gilead & NNI site 4 / palm 2 & Phase 2 \\
\hline IDX375 & Idenix & NNI site 4 / palm 2 & Phase 1 \\
\hline \multicolumn{4}{|l|}{ NS5A inhibitors } \\
\hline BMS-790052 & Bristol-Myers Squibb & NS5A domain 1 inhibitor & Phase 2 \\
\hline BMS-824393 & Bristol-Myers Squibb & NS5A inhibitor & Phase 1 \\
\hline AZD7295 & AstraZeneca & NS5A inhibitor & Phase 1 \\
\hline PPI-461 & Presidio & NS5A inhibitor & Phase 1 \\
\hline \multicolumn{4}{|c|}{ Indirect inhibitors / unknown mechanism of action } \\
\hline NIM811 & Novartis & Cyclophilin inhibitor & Stopped \\
\hline SCY-635 & Scynexis & Cyclophilin inhibitor & Phase 1 \\
\hline Alisporivir (Debio-025) & Debiopharm / Novartis & Cyclophilin inhibitor & Phase 2 \\
\hline Alinia (nitazoxanide) & Romark & PKR induction? & Phase 2 \\
\hline Celgosivir & BioWest & Alpha-glucosidase inhibitor & Stopped \\
\hline \multicolumn{4}{|c|}{ New formulations of current therapies } \\
\hline Taribavirin & Valeant & / ribavirin & Phase 2 \\
\hline Locteron (BLX-883) & Biolex & Interferon receptor type 1 & Phase 2 \\
\hline PEG-rIL-29 (peginterferon lambda) & ZymoGenetics / BMS & Interferon receptor type 3 & Phase 2 \\
\hline Joulferon (albinterferon alfa-2b) & HGS / Novartis & interferon receptor type 1 & Stopped \\
\hline
\end{tabular}




\section{TELAPREVIR}

Telaprevir (VX-950), an orally bioavailable, linear, ketoamide protease inhibitor, was initially investigated given alone or in combination with PEG-IFN alfa-2a $\pm \mathrm{RBV}$ in patients infected with HCV genotype 1 in a number of short-term studies [11-13]. A median maximum reduction of $-5.49 \log _{10} \mathrm{IU} / \mathrm{ml} \mathrm{HCV}$ RNA from baseline was observed in patients treated with telaprevir $(750 \mathrm{mg}$ three times daily) plus PEG-IFN alfa for 14 days. Mutations associated with clinical resistance to telaprevir were identified at 4 positions close to the NS3 catalytic domain - V36A/M/L, T54A, $\mathrm{R} 155 \mathrm{~K} / \mathrm{M} / \mathrm{S} / \mathrm{T}, \mathrm{A} 156 \mathrm{~S}$ (all three conferring low- to medium-level resistance) and A156T/V (conferring high-level resistance) $[14,15]$. Viral rebound due to selected drug-resistant mutants occurred in the majority of patients during monotherapy with telaprevir. However, a reduced frequency of resistant mutations and no viral breakthrough was observed in the combination studies.

Subsequently, the efficacy of telaprevir $(750 \mathrm{mg}$ three times daily) in combination with PEG-IFN 2a \pm RBV was studied in three large placebo-controlled phase $2 \mathrm{~b}$ trials in both treatment-naïve (PROVE $1, \mathrm{n}=$ 250; PROVE 2, $\mathrm{n}=323$ ) and treatment-experienced (PROVE 3, $\mathrm{n}=453$ patients with HCV genotype 1 [16-18]. Overall, SVR rates ranged from 67-69\% (PROVE 1/2) and 24-53\% (PROVE 3 ) in the telaprevir containing study arms compared to $41-46 \%$ and $14 \%$ in patients receiving SOC, respectively. Lower antiviral activities, higher break-through and high relapse rates (48\% and $53 \%$, respectively) were observed in the RBV-free study arms, indicating that RBV remains crucial for the achievement of sustained virologic response. Finally, discontinuation rates due to adverse events, including severe skin rashes, increased to nearly $26 \%$ in patients who received telaprevir for 24 weeks. Thus, in subsequent studies, telaprevir dosing was restricted to a maximum of 12 weeks. In a smaller, open-label study of telaprevir plus SOC in treatmentnaïve patients with HCV genotype 1, equally high SVR rates for telaprevir administered every 12 hours vs. 8 hours and given in combination with PEG-IFN alfa$2 \mathrm{a} / \mathrm{RBV}$ vs. PEG-IFN alfa-2b/RBV were observed [19].

Telaprevir was also investigated in patients with HCV genotype 2, 3 and 4. While a slightly reduced antiviral activity was observed in patients with genotype 2 infection, only minimal declines of HCV RNA concentrations were observed in patients infected with HCV genotypes 3 and 4 [20, 21].

Three landmark phase 3 trials, known as ADVANCE ( $n=1088)$, ILLUMINATE ( $n=540)$, both conducted in treatment-naïve patients, and REALIZE $(\mathrm{n}=662)$, conducted in treatment-experienced patients, evaluated the efficacy of telaprevir $(750 \mathrm{mg}$ three times daily) in combination with SOC for 24-48 weeks and 48 weeks overall treatment duration, respectively, in patients with HCV genotype 1 infection [22-24] (Fig. 1A/B).

The ADVANCE study had three study arms - 12 weeks of telaprevir plus SOC followed by SOC alone for 12 or 36 weeks, 8 weeks of telaprevir plus SOC followed by SOC alone for 16 or 40 weeks and SOC alone for 48 weeks. As part of a response-guided design, patients in the telaprevir-based treatment arms who had undetectable HCV RNA at week 4 and week 12 of treatment (eRVR, extended rapid virologic response) were eligible to receive 24 total weeks of therapy. Patients who did not meet this criterion but had undetectable HCV RNA at week 24 received 48 total weeks of therapy. The overall SVR rates ranged from $69 \%$ in patients who received 8 weeks of telaprevir to $75 \%$ in patients who received telaprevir for 12 weeks, compared to $44 \%$ in patients who received SOC alone. Nearly $60 \%$ (57\% and $58 \%$, respectively) of patients in the telaprevir-based study arms were eligible to undergo shortened treatment duration. Relapse rates were $9 \%, 9 \%$ and $28 \%$, respectively. Treatment discontinuation due to drug-related adverse events during the first 12 weeks of overall treatment occurred in $8 \%$, $7 \%$ and $4 \%$ of patients, respectively.

The ILLUMINATE trial was conducted in treatment-naive patients to investigate the benefit of longer treatment duration in patients who achieved an eRVR (65\%) following 12 weeks of telaprevir-based therapy. In this study, SVR rates were $92 \%$ in eRVR patients who received 24 total weeks of therapy compared to $88 \%$ in eRVR patients on 48 total weeks of treatment.

Taken together, eRVR was identified as a key predictor of SVR and the majority of patients were eligible to undergo shortened treatment duration with equally high SVR rates compared to the standard therapy duration of 48 weeks.

The REALIZE study evaluated the efficacy of a 12week triple combination treatment regimen followed by 36 weeks SOC or 4-week lead-in with SOC, followed by 12 weeks triple combination therapy, followed by 32 weeks of SOC in treatment-experienced patients with HCV genotype 1 (partial non-responders, $\geq 2 \log _{10}$ decline but detectable HCV RNA at treatment-week 12; null-responders, $<2 \log _{10}$ decline in HCV RNA at week 12; and relapsers) vs. SOC alone for 48 weeks. SVR rates for the three treatment arms were $64 \%, 66 \%$ and $17 \%$, respectively. Prior relapsers achieved SVR rates of $83 \%-88 \%$, while prior null responders achieved SVR rates in the range of $29 \%$ $33 \%$. A response-guided treatment-arm with shortening of treatment duration was not included in this study. Discontinuation due to adverse events occurred in $4 \%$ of the combined telaprevir study arms and in $3 \%$ of the control group. The relatively low discontinuation rates due to adverse events in all three phase 3 studies may be explained by precise management plans for telaprevir-induced rashes that involved expert dermatologist consultations at each study site.

During triple therapy with telaprevir plus PEG-IFN alfa/RBV, viral breakthrough associated with the selection of resistant variants was observed in $1-5 \%$ of treatment-naïve patients and in up to $25 \%$ of previous nonresponders. Moreover, variants conferring resistance to NS3 protease inhibitors were also detected in patients with viral relapse after the end of treatment. The longterm significance of these resistant variants is unknown but generally a decline in frequency over time has been observed [25]. However, in single patients, 

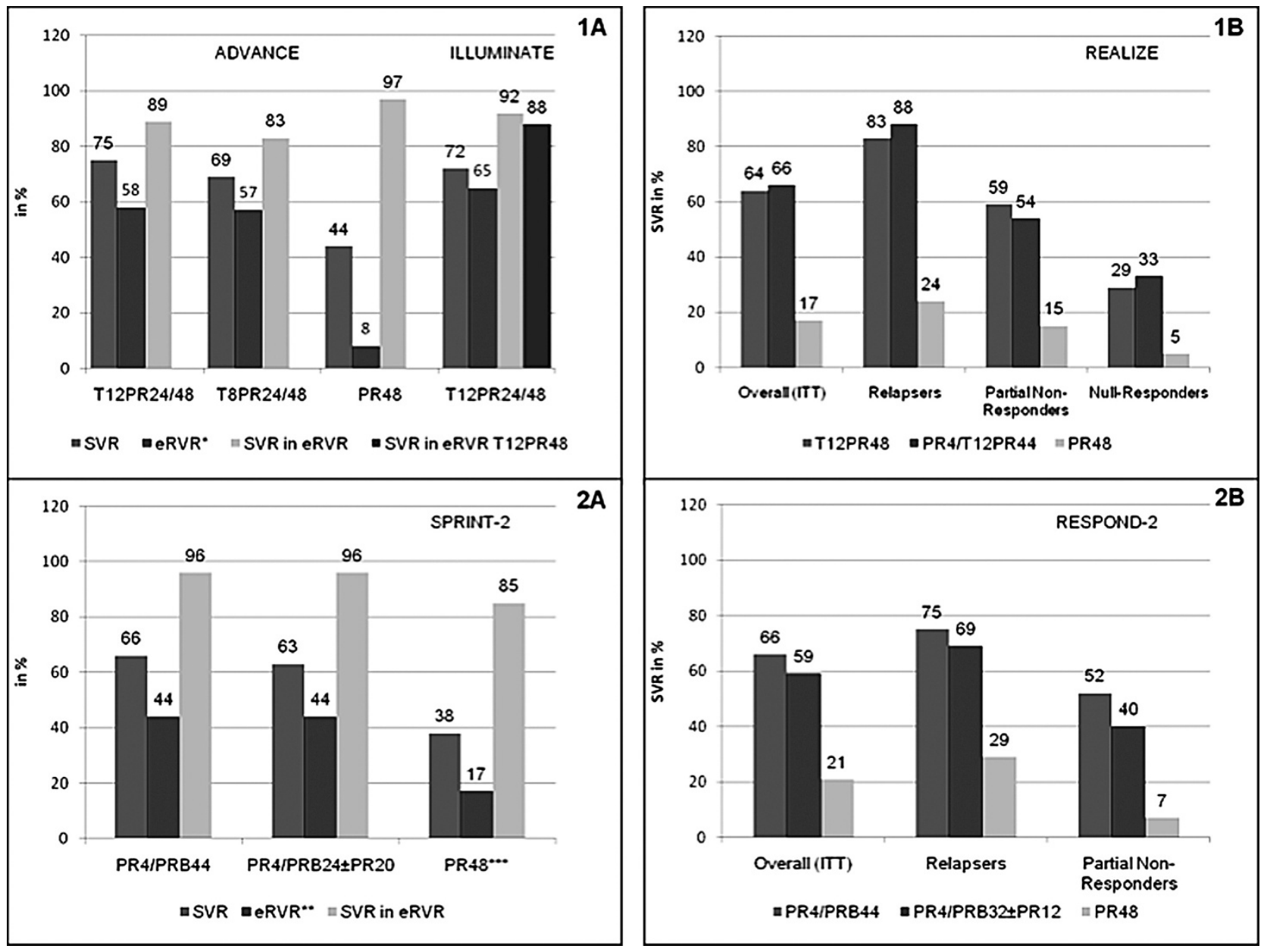

Fig. $1 \mathrm{~A} / \mathrm{B}$.

A) ADVANCE and ILLUMINATE were conducted in treatment-naïve patients with HCV genotype 1. The ADVANCE treatment arms were as follows: (i) 12 weeks of telaprevir (T) plus PEG-IFN alfa-2a and ribavirin (PR) followed by PR for 12 or 36 weeks, based on treatment response at week 4 and 12, (ii) 8 weeks of T plus PR followed by PR for 16 or 40 weeks, based on treatment response at week 4 and 12; (iii) PR alone for 48 weeks. In the ILLUMINATE trial, patients who achieved an eRVR were randomized to receive 12 weeks of T plus PR followed by PR for (i) 12 weeks or (ii) 24 weeks.

B) Treatment-experienced patients with HCV genotype 1 (REALIZE) received (i) 12 weeks of T plus PR followed by PR for 36 weeks, (ii) 4 weeks PR lead-in followed by TPR for 12 weeks followed by PR alone for 32 weeks (iii) PR alone for 48 weeks. In the REALIZE study, relapsers and non-responder (null-responders and partial non-responders) patients were enrolled.

*eRVR defined as HCV RNA negativity at week 4 and 12.

Fig. $2 A / B$.

A) SPRINT-2 treatment arms in treatment-naïve patients with HCV genotype 1 were as follows: (i) 4-week lead-in with PEGIFN alfa-2b plus ribavirin (PR) followed by 44 weeks of PR plus boceprevir (B); (ii) 4-week lead-in with PR followed by PR plus B for 24 weeks or followed by PR plus B for 24 weeks and PR for additional 20 weeks, based on treatment response at week 8 and 12; (iii) PR alone for 48 weeks.

B) The RESPOND-2 treatment schedule, conducted in treatment-experienced patients with HCV genotype 1 was as follows: (i) 4-week lead-in with PR followed by PR plus B for 44 weeks, (ii) 4-week lead in with PR followed by PR plus B for 32 weeks or followed by PR plus B for 32 weeks and PR for additional 12 weeks, based on treatment response at week 8 and 12; (iii) PR alone for 48 weeks.

**eRVR defined as HCV RNA negativity at week 8 through 24; ***in the SRINT-2 control arm, only standard RVR data (negative HCV RNA at week 8) are shown. ERVR results were not available at the time of submission of this manuscript.

low to medium levels of V36 and A156 variants were observed up to 4 years after telaprevir therapy [26].

\section{BOCEPREVIR}

In a phase $1 \mathrm{~b}$ study conducted in treatment-experienced patients with HCV genotype 1, administration of boceprevir (200 $\mathrm{mg}$ or $400 \mathrm{mg}$ three times daily), a peptidomimetic $\alpha$-ketoamide $\mathrm{HCV}$ protease inhibitor, with or without PEG-IFN alfa-2b resulted in mean maximum reductions of HCV RNA of up to 1.61 $\log _{10}$ and $2.88 \log _{10} \mathrm{IU} / \mathrm{ml}$, respectively [27]. Subsequently, a number of mutations conferring boceprevir resistance at low to medium levels were discovered in vivo - V36M/A, T54A/S, V55A, R155K/T, A156S, and V170A [28, 29]. 
As for telaprevir, reduced antiviral activities of boceprevir in HCV genotype 2/3 infected patients were reported.

A higher dose of boceprevir $(800 \mathrm{mg}$ three times daily) in combination with PEG-IFN alfa-2b and RBV was subsequently tested in a larger, phase 2 clinical trial (SPRINT-1; $\mathrm{n}=$ 595) in treatment-naïve patients with HCV genotype 1 infection [30]. Patients received either all three drugs in combination for 28 or 48 weeks or for 24 or 44 weeks after a previous 4-week lead-in period of PEG-IFN alfa-2b/RBV, or SOC for 48 weeks. SVR rates ranged from $54 \%$ for 28 weeks of triple therapy to $75 \%$ after a 4 -week lead-in period with PEG-IFN alfa-2b/RBV followed by 44 weeks of triple therapy compared to $38 \%$ in the control group. Treatment discontinuations due to adverse events (mainly anaemia and gastro-intestinal side effects) that occurred throughout the entire study appeared in 9\%$19 \%$ of patients receiving boceprevir compared to $8 \%$ in the control group.

In patients with prior non-response to SOC therapy, the addition of boceprevir to PEG-IFN alfa and RBV showed only slightly increased SVR rates compared to standard therapy in a phase $2 \mathrm{~b}$ study with suboptimal boceprevir/RBV dosing (14\% vs. $2 \%)$ [31].

The delayed start of boceprevir by four weeks, during which time patients received four weeks of SOC alone (lead-in), was designed to decrease the probability of resistance development. Among patients with a null-response to the 4-week lead-in treatment period (<1.0 $\log _{10} \mathrm{IU} / \mathrm{ml}$ HCV RNA reduction), the SVR rate was $25 \%$ for patients who continued 24 weeks of triple therapy and $55 \%$ for those who received 44 weeks of triple therapy. In contrast, patients who had a $>2 \log _{10} \mathrm{IU} / \mathrm{ml}$ decline in HCV RNA achieved SVR rates of $73-81 \%$. Thus, virologic response to the leadin allows for prediction of subsequent treatment success. However, even in lead-in-null-responders a significant improvement in SVR rates following subsequent triple therapy was observed.

In two phase 3 studies, a larger number of treatment-naïve (SPRINT-2; $\mathrm{n}=1097$ ) and treatment-experienced (RESPOND-2; $n=403$; partial non-responders and relapsers only) patients with HCV genotype 1 infection were enrolled to receive a 4-week lead-in with PEG-IFN alfa-2b/RBV alone, followed by either 44 weeks of triple combination therapy or a responseguided schedule with the possibility of stopping therapy at week 28 or week 36 of overall treatment duration (based on eRVR, defined as HCV RNA negative at week 8 and week 24), respectively [32, 33]. Among treatment-naïve patients, $66 \%$ in the 48 -week treatment group and 63\% in the response-guided therapy group achieved SVR compared to $38 \%$ in the control group. In treatment-experienced patients, $66 \%$ in the 48 -week treatment group and $59 \%$ in the responseguided therapy group achieved SVR compared to $21 \%$ in the control group. Overall, $44 \%$ of patients in the SPRINT-2 response-guided treatment arm and 46\% of patients in the RESPOND-2 response-guided treatment arm were eligible to undergo shortened treatment durations, based on eRVR results. Treatment discontinuations due to adverse events oc- curred in $12-16 \%$ of treatment-naïve patients and 8 $12 \%$ of treatment-experienced patients, compared to $16 \%$ and $3 \%$ in the control groups, respectively (Fig. $2 \mathrm{~A} / \mathrm{B})$.

\section{OTher Protease INHIBITORS}

A number of second-generation NS3/4A protease inhibitors are currently in early clinical development. Among these, danoprevir (RG7227), TMC435, vaniprevir (MK-7009), BI201335, narlaprevir (SCH900518), BMS-650032, PHX1766; ACH-1625, ABT-450, MK-5172, GS-9256, and GS-9451 have all been tested in phase 1 and/or phase 2 clinical trials [34-46]. Overall, these compounds exhibit a high antiviral activity in HCV genotype 1 patients and recently reported phase 2 results were comparable to, or even surpassed SVR results obtained with telaprevir and boceprevir [34, 39, 44].

Potential advantages of these second-generation protease inhibitors include improved pharmacokinetics (one to two times daily dosing), broader genotypic activity, coverage of first generation protease inhibitor resistance mutations and better tolerability. In addition, ritonavir boosting is being investigated in a number of protease inhibitors, including narlaprevir and danoprevir, to reduce side effects and to enhance patient exposure to the latter agents, thereby potentially overcoming resistance issues and allowing less frequent dosing.

Overlapping resistance profiles have been reported for all NS3 protease inhibitors that are currently in phase 2-3 development [47].

\section{Antivirals TARgeting the HCV RNA Polymerase}

\section{NS5B POLYMerase InHibitors}

The active site of the HCV NS5B polymerase represents an interesting target for anti-HCV therapies as it forms a highly conserved structure across all $\mathrm{HCV}$ genotypes [48]. Currently, two classes of NS5B polymerase inhibitors can be distinguished - nucleoside or nucleotide analogue inhibitors that mimic the natural substrates of the RNA-dependent RNA-polymerase and are incorporated at the active site of the enzyme into the elongated RNA where they act as chain terminators, and non-nucleoside analogue inhibitors, representing a heterogeneous group of antiviral compounds that bind to different allosteric enzyme sites, resulting in a conformational protein change before the elongation complex is formed (Table 1).

\section{NuCLEOS(T)IDE INHIBITORS}

Nucleos $(\mathrm{t})$ ide polymerase inhibitors target the active binding site of NS5B, with potential activity against all HCV genotypes. Despite promising results from early clinical studies, further development of the first two nucleoside polymerase inhibitors, valopicitabine and R1626, was halted due insufficient antiviral activity and severe adverse events [49-51].

RG7128, a prodrug of the cytidine nucleoside analogue PSI-6130, is currently under investigation in an 
ongoing placebo-controlled phase $2 \mathrm{~b}$ study in treatment-naïve patients with HCV genotype 1 or 4 ( $n=$ 408). Interim results on complete early virologic response (cEVR; negative HCV RNA at week 12) showed up to $87 \%$ HCV RNA negativity for patients who received RG7128 at a dose of $1000 \mathrm{mg}$ twice daily for 12 weeks plus SOC and no resistance related viral breakthrough was reported [52].

PSI-7977, a chirally pure isomer form of PSI-7851, has yielded promising early data with high RVR rates (88-94\%) across different dose groups plus SOC in treatment-naïve patients with HCV genotype 1 [53]. The nucleotide analogue PSI-938 is still in the early stages of clinical development [54].

\section{NON-NUCLEOSIDE INHIBITORS}

The structure of the NS5B polymerase resembles a characteristic "right hand motif", consisting of finger, palm and thumb domains. At least 4 different allosteric binding sites have been identified for the inhibition of the NS5B polymerase by non-nucleoside inhibitors - (i) a benzimidazole (thumb 1)-, (ii) a thiophene (thumb 2)-, (iii) a benzothiadiazine (palm 1)-, and (iv) a benzofuran (palm 2)-binding site [47]. As non-nucleoside inhibitors bind more distantly to the active site of NS5B, resistant mutations occur more frequently in these compounds.

\section{(i) Non-nucleoside site 1 inbibitors}

(thumb 1 / benzimidazole site)

BI 207127, BILB1941, and MK-3281 are non-nucleoside-site 1 inhibitors that have been shown to exhibit low to medium antiviral activity in phase 1 clinical trials [55-57]. Four weeks of BI 207127 (600 mg three times daily) in combination with PEG-IFN alfa$2 \mathrm{a} / \mathrm{RBV}$ has resulted in a median reduction of 5.6 $\log _{10}$ HCV RNA in treatment-naïve genotype 1 patients and no viral breakthrough was observed [58]. Results of further studies have to be awaited. The further development of BILB1941 and MK-3281 was halted due to gastrointestinal adverse events.

\section{(ii) Non-nucleoside site 2 inbibitors}

(thumb 2 / thiophene site)

Interim results from a phase 1 trial investigating different doses of filibuvir (PF-00868554), a non-nucleoside site 2 inhibitor, in combination with SOC for 4 weeks followed by SOC for 44 weeks have shown similar SVR (at 12 weeks follow-up) results for the different filibuvir groups compared to the SOC group, indicating that longer dosing of filibuvir may be necessary [59]. Other site 2-inhibitors include VX-759, VX-916, and VX-222 [60-62]. However, at this point, only VX222 has progressed to phase 2 developments.

\section{(iii) Non-nucleoside site 3 inhibitors} (palm 1 / benzothiadiazine site)

A phase 2 trial of ANA598 in combination with PEGIFN alfa-2a/RBV in treatment-naive patients with $\mathrm{HCV}$ genotype 1 is currently ongoing. It was recently reported that $75 \%$ of patients who received $400 \mathrm{mg}$ of ANA598 twice daily achieved undetectable HCV RNA levels at treatment week 12 [63]. Other site 3-palm 1- inhibitors include ABT-072 and ABT-333, both of which have entered phase 2 clinical trials [64].

\section{(iv) Non-nucleoside site 4 inbibitors}

(palm 2 / benzofuran site)

Monotherapy with HCV-796 (nesbuvir) showed low antiviral activity in patients with HCV genotype 1. In addition, selection of resistant variants and viral breakthrough was observed in several patients [65]. Further drug development was suspended due to abnormal liver enzyme elevations in a subsequent phase 2 study. GS-9190 (tegobuvir) displayed low antiviral activity in a phase 1 clinical study and drug-resistant variants were observed. However, GS-9190 has entered phase 2 clinical trials, both in combination with SOC and with the protease inhibitor GS-9256 \pm RBV [66]. Finally, IDX375 also binds to the palm pocket and is currently in phase 1 clinical trials [67].

\section{NS5A INHIBITORS}

Inhibitors of NS5A are potentially active against all HCV genotypes. BMS-790052 binds to domain I of the NS5A protein, which is crucial for the regulation of HCV replication, assembly and release. Following the promising results from a phase 1 study [68], BMS790052 is currently under investigation in a number of phase 2 clinical trials. Recently, interim data were released from a phase 2 study investigating different doses of BMS-790052 in combination with SOC. RVR rates were $83 \%$ and $92 \%$ in patients who received 10 $\mathrm{mg}$ and $60 \mathrm{mg}$ BMS-790052 once daily, respectively. In addition, undetectable HCV RNA levels at week 12 (cEVR) were observed in $83 \%$ of patients [69]. Other NS5A inhibitors include BMS-824393, AZD7295, and PPI-461 [70-72].

\section{DAA COMBINATION THERAPIES}

Treatment discontinuation rates due to interferon-associated side effects are commonly observed, especially in the routine daily practice [73]. Therefore, one of the primary future goals of DAA therapy is to control viral replication or even to achieve SVR in interferonfree regimens. In the placebo-controlled INFORM-1 study, combinations of different doses of a polymerase inhibitor (RG7128) and a NS3/4A protease inhibitor (danoprevir) were tested in 87 treatment-naïve and -experienced patients with HCV genotype 1 for up to 2 weeks [74]. At the highest doses tested (1000 mg RG7128 and $900 \mathrm{mg}$ danoprevir twice daily), 63\% of treatment-naïve patients and $25 \%$ of treatment-experienced patients achieved undetectable HCV RNA after 2 weeks of combination therapy and only one patient experienced viral rebound without exhibiting resistant mutations.

Several other drug combinations are actively being investigated. In a phase 2 study of the NS3 protease inhibitor GS-9256 (75 mg twice daily) plus the nonnucleoside NS5B polymerase inhibitor tegobuvir (40 $\mathrm{mg}$ twice daily) alone or in combination with RBV or PEG-IFN alfa/RBV for up to 28 days, viral breakthrough was observed for the combination of the two direct antiviral compounds only. This clearly shows 
that two drugs with a low barrier to resistance are insufficient for continuous suppression of virus replication. Interestingly, the addition of RBV enhanced antiviral activity and reduced viral breakthrough rates, even in the absence of PEG-IFN alfa [75].

An IFN-sparing triple combination therapy with the NS3 protease inhibitor BI 201335 (12mg once daily) and the non-nucleoside polymerase inhibitor BI 207127 (400 $\mathrm{mg}$ or $600 \mathrm{mg}$ three times daily) plus RBV resulted in residual or even undetectable HCV RNA levels after 4 weeks in all patients treated with the higher dose of BI 207127 [76].

Finally, in an ongoing trial of HCV genotype 1 null-responders treated with the NS5A inhibitor BMS-790052 plus the NS3 protease inhibitor BMS650032 alone or in combination with PEG-IFN alfa/RBV for 24 weeks, 5/11 and 9/10 patients achieved cEVR, respectively. All patients with viral breakthrough in the DAA-only combination regimen (6/11) were genotype 1 a patients. This important observation indicates that different antiviral activities of DAAs may be present on the HCV subtype level [77]. An overview of current combination therapy trials is given in Table 2.

Overcoming drug resistance will be the primary challenge in DAA combination therapies and nucleos(t)ide analogues with a high genetic barrier to resistance and/or drug combinations that have a genetic barrier of four or more mutations may be required [78] (see Table 3). Future trials need to address the tolerability and safety of long-term DAA administration and whether SVR can be achieved without the addition of PEG-IFN alfa/RBV.

\section{EmERging MECHANISMS}

\section{CYCLOPHILIN INHIBITORS}

Cyclophilins are ubiquitous proteins in human cells that are involved in protein folding. Moreover, cyclophilins participate in HCV replication as functional regulators of the HCV NS5B polymerase.

The cyclophilin inhibitor Debio-025 (alisporivir), a cyclosporine A analogue, showed antiviral activity in patients infected with different HCV genotypes (1-4) during monotherapy and in combination studies with PEG-IFN alfa. Maximum $\log _{10}$ changes in HCV RNA of up to 4.75 were observed in patients with HCV genotypes 1 or 4 who received $1000 \mathrm{mg}$ Debio-025 in combination with PEG-IFN alfa-2a/RBV for 4 weeks [79]. Interestingly, there is even one case report of a genotype 3a patient who achieved SVR following 4 weeks of Debio-025 $1000 \mathrm{mg} /$ day as monotherapy [80]. Despite the selection of HCV variants with mutations clustering in the NS5A gene that showed resistance to Debio-025 in the HCV replicon system [81], no viral breakthrough has been observed in clinical studies so far.

SCY-635 is another non-immunosuppressive analogue of cyclosporine A that exhibits potent suppression of HCV. Different doses of SCY-635 were investigated in patients infected with HCV genotype 1 and a mean maximum decline of $2.3 \log _{10} \mathrm{IU} / \mathrm{ml}$ in viral load was observed after 15 days of $900 \mathrm{mg}$ SCY-635 monotherapy [82]. No viral rebound was observed during SCY-635 therapy. However, minimal evidence of resistance selection was observed within NS5B [83].

\section{SILIBININ}

Silymarin, an extract of milk thistle (Silybum marianum) with antioxidant activity has been used as selfmedication for liver diseases over centuries [84]. Silibinin is one of the six major flavonolignans in silymarin. Though its mechanism of action and treatment efficacy is not yet fully understood, it was recently reported that silibinin is a direct inhibitor of the NS5B polymerase [85]. Other findings suggest that silymarin blocks virus entry and transmission, possibly by targeting the host cell [86].

Intravenous silibinin was investigated in 36 non-responders to prior PEG-IFN-based antiviral therapy and showed a significant decline in HCV RNA $(0.55$ to $3.02 \log _{10} \mathrm{IU} / \mathrm{ml}$ ) after 7 days and a further decrease after additional 7 days in combination with PEG-IFN alfa-2a/RBV in the range of 1.63 to 4.85 $\log _{10} \mathrm{IU} / \mathrm{ml}$. HCV RNA became undetectable in 7 patients on 15 or $20 \mathrm{mg} / \mathrm{kg}$ silibinin at week 12 of total treatment [87]. Recently, it was reported that a short course of intravenous silibinin (2 days of $1400 \mathrm{mg}$ ) could be used as a rescue approach in patients showing non-response to SOC [88]. Studies in larger patient cohorts including resistance analyses are underway.

\section{New Formulations of Current Therapies}

\section{RIBAVIRIN ANALOGUES}

Adverse haematological effects associated with RBV are commonly observed and have prompted the development of taribavirin, a prodrug that is converted to RBV and is concentrated in the liver, leading to reduced RBV uptake by red blood cells. In two phase 3 trials, administration of taribavirin $(600 \mathrm{mg}$ twice daily) plus PEG-IFN alfa-2a or $-2 b$ failed to achieve noninferiority to administration of weight-based RBV plus PEG-IFN alfa-2a/b [89, 90]. In a recently completed phase $2 \mathrm{~b}$ trial, weight-based taribavirin was non-inferior compared to weight-based RBV, with fewer haematological side effects [91]. However, anaemia rates increased with higher taribavirin dosing and the dropout rates for anaemia did not differ between the two study drugs. Therefore, the future role of taribavirin remains to be elucidated.

\section{NEW INTERFERONS}

Albinterferon alfa-2b (Joulferon) is a recombinant protein consisting of interferon alfa- $2 \mathrm{~b}$ fused to human albumin that can be administered every two or four weeks due to a longer half-life compared to the currently marketed pegylated interferons. However, albinterferon was neither better tolerated nor did it show superior efficacy in patients with HCV genotype 1 or $2 / 3$ in two large phase 3 studies [92, 93]. Owing to concerns expressed by the regulatory authorities regarding the drug's benefit/risk ratio, the approval process of albinterferon was recently suspended. 


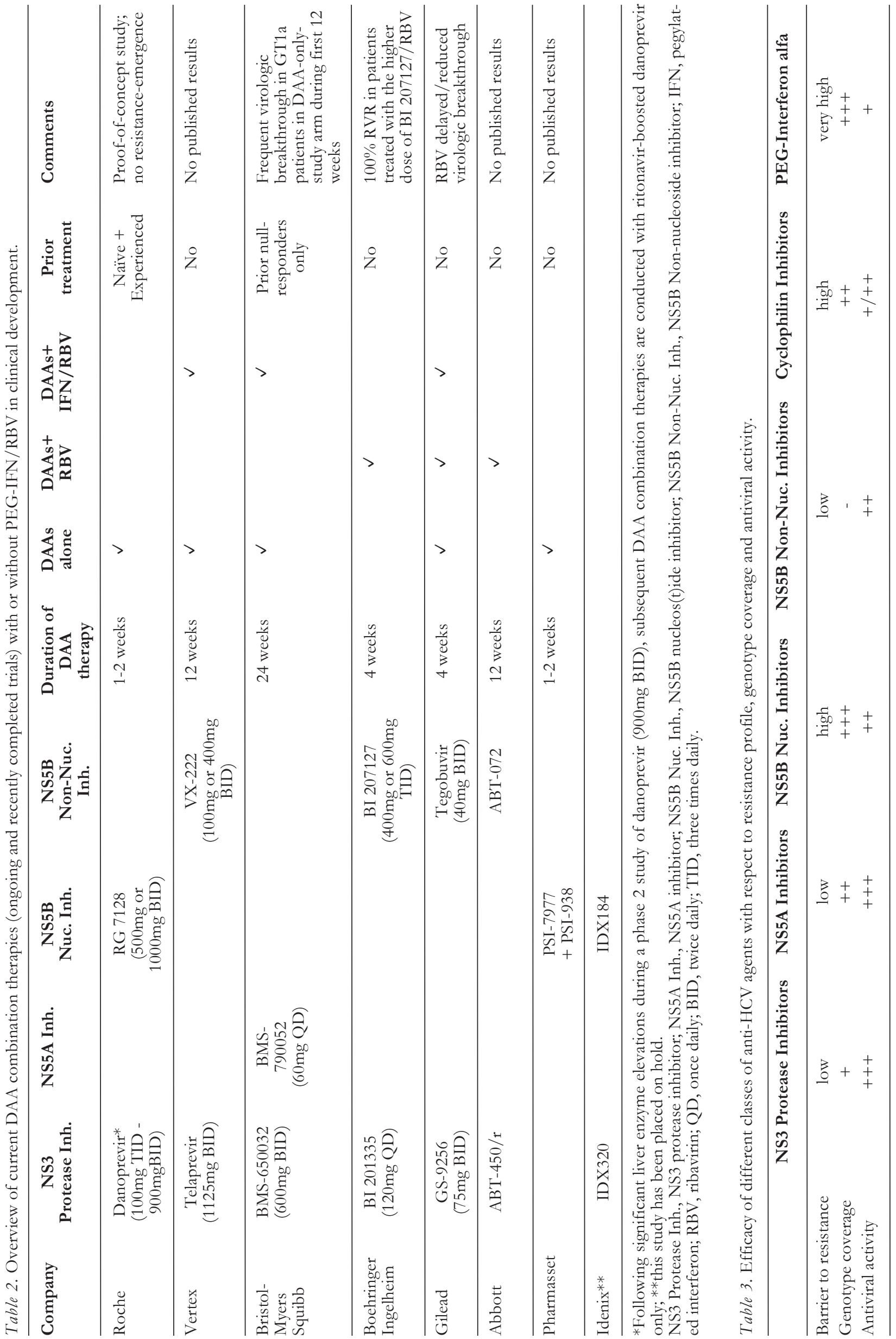


Locteron is a controlled release formulation of interferon alfa-2b that can be administered every two weeks. Week 12 interim results from a phase $2 \mathrm{~b}$ study have shown a similar reduction in HCV RNA and a reduction of flu-like symptoms by $57 \%$ for locteron at a dose of $480 \mu \mathrm{g}$ compared to PEG-IFN alfa-2b in treatment-naïve patient with HCV genotype 1 [94]. SVR results have not yet been reported.

A non-pegylated, type I interferon alpha-formulation, consensus interferon, has recently been approved in combination with ribavirin for non-responders to PEG-IFN therapy [95]. Finally, PEG-IFN lambda (PEG-rIL-29) is a type III interferon that binds to a unique receptor with more limited distribution than the type I interferon receptor used by interferon alpha. In a phase $1 \mathrm{~b}$ trial, 56 treatment-naïve patients and patients who relapsed after SOC were enrolled to receive different doses of PEG-IFN lambda (ranging from 0.5 to $3.0 \mu \mathrm{g} / \mathrm{kg}$ ) administered every two weeks or weekly with or without daily RBV for four weeks. Antiviral activity was seen at all dose levels with a mean maximum change of HCV RNA from baseline of $3.27 \log _{10} \mathrm{IU} / \mathrm{ml}$ in treatment naïve patients treated with weekly PEG-IFN lambda $(1.5 \mu \mathrm{g} / \mathrm{kg})$ plus RBV [96]. In addition, minimal flu-like symptoms and no significant haematological side effects were observed. Phase 2 trials are currently ongoing.

\section{CONCLUSIONS}

While treatment success in patients with HCV genotype 1, the most prevalent genotype in Europe and the USA, remains suboptimal with the current standard of care, a number of promising direct-acting antiviral compounds offer new hope for a cure.

Recently completed pivotal phase 3 studies of the currently most advanced NS3/4A protease inhibitors, telaprevir and boceprevir, have shown SVR rates in the range of $69-75 \%$ and $63-66 \%$, respectively, in treatment-naïve patients with HCV genotype 1 infection. Additional important findings include the successful application of shortened treatment durations of $24 / 28$ weeks in $50-65 \%$ of patients, based on extended rapid on-treatment response. Finally, patients who failed a prior course of interferon-based therapy may also be successfully cured, with SVR rates of 64$66 \%$ and $59-66 \%$ in telaprevir- and boceprevir-based regimens, respectively. No protease inhibitor head-tohead studies have been conducted so far.

Nucleos $(t)$ ide and non-nucleoside inhibitors of the HCV NS5B polymerase have shown promising antiviral efficacy in early clinical studies. Unlike protease inhibitors, which are mostly active in patients with HCV genotype 1 only, nucleos $(\mathrm{t})$ ide polymerase inhibitors bind to the highly conserved centre of the HCV polymerase, with the potential advantage of equal effectiveness in different HCV genotypes. However, SVR results from larger studies have to be awaited.

At present, a number of studies focus on different combinations of different HCV protease and polymerase inhibitors with or without the addition of SOC. While a rapid and profound decline in HCV RNA was observed in most of these studies, sustained virologic response may be only achieved with combi- nation therapies using at least 3 compounds or with PEG-IFN/RBV as a therapeutic backbone for the foreseeable future.

While HCV protease and polymerase inhibitors are likely to take the lead in future anti-HCV drug regimens, there are a number of additional therapeutic approaches that may eventually find their place within the HCV armamentarium. Among these, inhibitors of the non-structural protein $5 \mathrm{~A}$ and cyclophilin inhibitors are currently the furthest along in the pipeline.

With the addition of new antiviral compounds to standard therapy, a number of additional side effects unrelated to SOC have been observed, and increased treatment-discontinuation rates have been reported. Consequently, successful management of these side effects will gain in importance and will have increasing influence on treatment outcomes. In addition, frequent dosing intervals (i.e. three times daily) may lead to increased non-adherence outside of clinical trials and more patient-friendly formulations have to be developed.

One of the major challenges of future anti-HCV treatment regimens will be the emerging field of DAA drug resistance. Relatively low genetic barriers to resistance have been reported for HCV protease inhibitors and non-nucleoside polymerase inhibitors as compared to nucleos $(\mathrm{t})$ ide HCV polymerase inhibitors that appear to have a high genetic barrier to resistance. However, HCV eradication may not be achieved with monotherapy from either substance group and drug combinations with non-cross-resistance patterns have to be further evaluated. In addition, pre-existing resistant variants and their potential long-term persistence have to be taken into account for the selection of optimal treatment and re-treatment strategies. Finally, the potential risks of drug-drug interactions, especially in patients with HIV co-infection who are on antiretroviral therapy, will likely gain in importance, while numbers of patients treated with DAAs are increasing. Therapeutic drug monitoring may eventually play an important role in the management of these interactions [97].

\section{REFERENCES}

1. World Health Organization. Hepatitis C. available at: http://www.who. int/csr/disease/hepatitis/whocdscsrlyo 2003/en/index4.html; accessed on 01.12.2010.

2. Fried MW, Shiffman ML, Reddy KR et al. Peginterferon alfa-2a plus ribavirin for chronic hepatitis $C$ virus infection. N Engl J Med 2002; 347: 975-982.

3. Hadziyannis SJ, Sette H, Jr., Morgan TR et al. Peginterferon-alpha2a and ribavirin combination therapy in chronic hepatitis C: a randomized study of treatment duration and ribavirin dose. Ann Intern Med 2004; 140: 346-355.

4. Manns MP, McHutchison JG, Gordon SC et al. Peginterferon alfa- $2 \mathrm{~b}$ plus ribavirin compared with interferon alfa- $2 \mathrm{~b}$ plus ribavirin for initial treatment of chronic hepatitis C: a randomised trial. Lancet 2001; 358: 958-965.

5. Zeuzem S, Hultcrantz R, Bourliere M et al. Peginterferon alfa-2b plus ribavirin for treatment of chronic hepatitis $C$ in previously untreated patients infected with $\mathrm{HCV}$ genotypes 2 or 3. J Hepatol 2004; 40: 993-999.

6. Kim JL, Morgenstern KA, Lin C et al. Crystal structure of the hepatitis C virus NS3 protease domain complexed with a synthetic NS4A cofactor peptide. Cell 1996; 87: 343-355. 
7. Lohmann V, Korner F, Koch J et al. Replication of subgenomic hepatitis $\mathrm{C}$ virus RNAs in a hepatoma cell line. Science 1999; 285: 110-113.

8. Moradpour D, Penin F, Rice CM. Replication of hepatitis C virus. Nat Rev Microbiol 2007; 5: 453-463.

9. Wakita T, Pietschmann T, Kato T et al. Production of infectious hepatitis $\mathrm{C}$ virus in tissue culture from a cloned viral genome. Nat Med 2005; 11: 791-796.

10. Lamarre D, Anderson PC, Bailey M et al. An NS3 protease inhibitor with antiviral effects in humans infected with hepatitis C virus. Nature 2003; 426: 186-189.

11. Forestier N, Reesink HW, Weegink CJ et al. Antiviral activity of telaprevir (VX-950) and peginterferon alfa-2a in patients with hepatitis C. Hepatology 2007; 46: 640-648.

12. Lawitz E, Rodriguez-Torres M, Muir AJ et al. Antiviral effects and safety of telaprevir, peginterferon alfa- $2 \mathrm{a}$, and ribavirin for 28 days in hepatitis C patients. J Hepatol 2008; 49: 163-169.

13. Reesink HW, Zeuzem S, Weegink CJ et al. Rapid decline of viral RNA in hepatitis C patients treated with VX-950: a phase Ib, placebo-controlled, randomized study. Gastroenterology 2006; 131: 997-1002.

14. Kieffer TL, Sarrazin C, Miller JS et al. Telaprevir and pegylated interferon-alpha-2a inhibit wild-type and resistant genotype 1 hepatitis $C$ virus replication in patients. Hepatology 2007; 46: 631-639.

15. Sarrazin C, Kieffer TL, Bartels D et al. Dynamic hepatitis C virus genotypic and phenotypic changes in patients treated with the protease inhibitor telaprevir. Gastroenterology 2007; 132: 1767-1777.

16. Hezode C, Forestier N, Dusheiko G et al. Telaprevir and peginterferon with or without ribavirin for chronic HCV infection. N Engl J Med 2009; 360: 1839-1850.

17. McHutchison JG, Everson GT, Gordon SC et al. Telaprevir with peginterferon and ribavirin for chronic HCV genotype 1 infection. N Engl J Med 2009; 360: 1827-1838.

18. McHutchison JG, Manns MP, Muir AJ et al. Telaprevir for previously treated chronic HCV infection. N Engl J Med 2010; 362: 1292-1303.

19. Marcellin P, Forns X, Goeser T et al. Telaprevir Is Effective Given Every 8 or 12 Hours With Ribavirin and Peginterferon Alfa-2a or $-2 \mathrm{~b}$ to Patients With Chronic Hepatitis C. Gastroenterology 2010. Epub ahead of print.

20. Benhamou Y, Moussalli J, Ratziu V et al. Activity of telaprevir monotherapy or in combination with peginterferon-alfa$2 \mathrm{a}$ and ribavirin in treatment-naive genotype 4 hepatitis-Cpatients: final results of study C210. Hepatology 2010; 52: 719A.

21. Foster GR, Hezode C, Bronowicki JP et al. Activity of telaprevir alone or in combination with peginterferon alfa-2a and ribavirin in treatment-naive genotype 2 and 3 hepatitisC patients: final results of study C209. J Hepatol 2010; 52: S27.

22. Jacobson IM, McHutchison JG, Dusheiko G et al. Telaprevir in combination with peginterferon and ribavirin in genotype $1 \mathrm{HCV}$ treatment-naive patients: final results of phase 3 ADVANCE study. Hepatology 2010; 52: 427A.

23. Vertex Pharmaceuticals Inc. $65 \%$ of people whose prior treatment for hepatitis C was unsuccessful achieved SVR (viral cure) with telaprevir-based therapy in phase 3 REALIZE study. Press Release 2010; http:/ / investors.vrtx.com/releasedetail.cfm?ReleaseID_505239; accessed on 01.12.2010.

24. Sherman KE, Flamm SL, Afdhal NH et al. Telaprevir in combination with peginterferon alfa- $2 \mathrm{a}$ and ribavirin for 24 or 48 weeks in treatment-naive genotype $1 \mathrm{HCV}$ patients who achieved an extended rapid viral response: final results of phase 3 ILLUMINATE study. Hepatology 2010; 52: 401A.

25. Zeuzem S, Sulkowski MS, Zoulim F et al. Long-term follow-up of patients with chronic hepatitis $C$ treated with telaprevir in combination with peginterferon alfa-2a and ribavirin: interim analysis of the extend study. Hepatology 2010; 52: 436A.

26. Susser S, Forestier N, Vermehren J et al. Decline of detectable resistance mutations within the HCV NS3 protease quasispecies during long-term follow-up after treatment with telaprevir. J Hepatol 2010; 52: S300.

27. Sarrazin C, Rouzier R, Wagner F et al. SCH 503034, a novel hepatitis $C$ virus protease inhibitor, plus pegylated interferon alpha-2b for genotype 1 nonresponders. Gastroenterology 2007; 132: 1270-1278.

28. Susser S, Welsch C, Wang Y et al. Characterization of resistance to the protease inhibitor boceprevir in hepatitis C virus-infected patients. Hepatology 2009; 50: 1709-1718.

29. Vermehren J, Susser S, Karey U et al. Clonal analysis of mutations selected in the HCV NS3 protease domain of genotype 1 non-responders sequentially treated with boceprevir (SCH503034) and/or pegylated interferon alfa-2b (PEGIFN alfa-2b). Hepatology 2009; 50: 1040A.

30. Kwo PY, Lawitz EJ, McCone J et al. Efficacy of boceprevir, an NS3 protease inhibitor, in combination with peginterferon alfa- $2 \mathrm{~b}$ and ribavirin in treatment-naive patients with genotype 1 hepatitis C infection (SPRINT-1): an open-label, randomised, multicentre phase 2 trial. Lancet 2010; 376: 705-716.

31. Schiff E, Poordad F, Jacobson I et al. Boceprevir combination therapy in null responders: Response dependent on interferon resonsiveness. J Hepatol 2008; 48: S46.

32. Bacon BR, Gordon SC, Lawitz E et al. HCV RESPOND-2 final results: High sustained virologic response among genotype 1 previous non-responders and relapsers to peginterferon/ribavirin when re-treated with boceprevir plus pegintron (peginterferon alfa-2b)/ribavirin. Hepatology 2010; 52: 430A.

33. Poordad F, McCone J, Bacon BR et al. Boceprevir (BOC) combined with peginterferon alfa-2b/ribavirin $(\mathrm{P} / \mathrm{R})$ for treatment-naive patients with hepatitis $\mathrm{C}$ virus (HCV) genotype $(G)$ 1: SPRINT-2 final results. Hepatology 2010; 52: $402 \mathrm{~A}$.

34. Berg T, Dieterich DT, Lalezari JP et al. Virological response and safety of 4 weeks treatment with the protease inhibitor BI 201335 combined with 48 weeks of peginterferon alfa 2a and ribavirin for treatment of HCV GT-1 patients who failed peginterferon / ribavirin. Hepatology 2010; 52: 704A.

35. Brainard DM, Petry A, van Dyck K et al. Safety and antiviral activity of MK-5172, a novel HCV NS3/4A protease inhibitor with potent activity against known resistance mutants, in genotype 1 and $3 \mathrm{HCV}$-infected patients. Hepatology 2010; 52: 706A.

36. de Bruijne J, Bergmann JF, Reesink HW et al. Antiviral activity of narlaprevir combined with ritonavir and pegylated interferon in chronic hepatitis C patients. Hepatology 2010; 52: 1590-9.

37. Detishin V, Haazen W, Robison $\mathrm{H}$ et al. Virological response, safety, and pharmacokinetic profile following singleand multiple-dose administration of ACH-0141625 protease inhibitor to healthy volunteers and HCV genotype-1 patients. J Hepatol 2010; 52: S468.

38. Forestier N, Larrey D, Guyader D et al. Treatment of chronic hepatitis C Patients with the NS3/4A protease inhibitor danoprevir (ITMN-191/RG7227) leads to robust reductions in viral RNA: a phase $1 \mathrm{~b}$ multiple ascending dose study. J Hepatol 2010; Epub ahead of print.

39. Fried MW, Buti M, Dore GJ et al. Efficacy and safety of TMC435 in combination with peginterferon alfa-2a and ribavirin in treatment-naive genotype-1 HCV patients: 24-week interim results from the PILLAR study. Hepatology 2010; 52: $403 \mathrm{~A}$.

40. Goldwater R, DeMicco MP, Zong J et al. Safety, pharmacokinetics, and antiviral activity of single oral doses of the HCV NS3 protease inhibitor GS 9256. Hepatology 2010; 52: $717 \mathrm{~A}$. 
41. Hotho D, de Bruijne J, O'Farrell AM et al. Accelerated clinical trial design to assess the safety, tolerability and anti-viral activity of PHX1766, a novel HCV NS3/4A protease inhibitor, in healthy volunteers and chronic hepatitis $\mathrm{C}$ patients. Hepatology 2009; 50: 1031A.

42. Lawitz E, Hill JM, Marbury TC et al. Three-day, dose-ranging study of the HCV NS3 protease inhibitor GS-9451. Hepatology 2010; 52: 714A.

43. Lawitz E, Gaultier F, Poordad F et al. 4-week virologic response and safety of ABT-450 given with low-dose ritonavir (ABT-450/r) in combination with pegylated interferon alpha-2a and ribavirin (SOC) after 3-day monotherapy in genotype 1 (GT1) HCV-infected treatment-naive subjects. Hepatology 2010; 52: 878A.

44. Manns MP, Gane EJ, Rodriguez-Torres M et al. Sustained viral response (SVR) rates in genotype 1 treatment-naive patients with chronic hepatitis $\mathrm{C}$ (CHC) infection treated with vaniprevir (MK-7009), a NS3/4A protease inhibitor, in combination with pegylated interferon alfa-2a and ribavirin for 28 days. Hepatology 2010; 52: 361A.

45. Pasquinelli C, Eley T, Villegas C et al. Safety, tolerability, pharmacokinetics and antiviral activity following single- and multiple-dose administration of BMS-650032, a novel HCV NS3 inhibitor, in subjects with chronic genotype $1 \mathrm{HCV}$ infection. Hepatology 2009; 50: 411A.

46. Terrault NA, Cooper C, Balart LA et al. Phase II randomised, partially-blind, parallel-group study of oral danoprevir (RG7227) with PegIFNalfa-2a (PEGASYS) plus ribavirin in treatment-naive genotype 1 patients with $\mathrm{CHC}$ : results of planned week 12 interim analysis of the ATLAS study. Hepatology 2010; 52: 335A.

47. Sarrazin C Zeuzem S. Resistance to direct antiviral agents in patients with hepatitis C virus infection. Gastroenterology 2010; 138: 447-462.

48. Lesburg CA, Cable MB, Ferrari E et al. Crystal structure of the RNA-dependent RNA polymerase from hepatitis C virus reveals a fully encircled active site. Nat Struct Biol 1999; 6: 937-943.

49. Lawitz E, Nguyen T, Younes Z et al. Clearance of HCV RNA with valopicitabine (NM283) plus peg-interferon in treatment-naive patients with HCV-1 infection: Results at 24 and 48 weeks. J Hepatol 2007; 46: S9.

50. Pockros PJ, Nelson D, Godofsky E et al. R1626 plus peginterferon Alfa-2a provides potent suppression of hepatitis C virus RNA and significant antiviral synergy in combination with ribavirin. Hepatology 2008; 48: 385-397.

51. Roberts SK, Cooksley G, Dore GJ et al. Robust antiviral activity of R1626, a novel nucleoside analog: a randomized, placebo-controlled study in patients with chronic hepatitis C. Hepatology 2008; 48: 398-406.

52. Jensen DM, Wedemeyer H, Herring RW et al. High rates of early viral response, promising safety profile and lack of resistance-related breakthrough in HCV GT $1 / 4$ patients treated with RG7128 plus PEGIFN alfa-2a (40KD)/RBV: planned week 12 interim analysis from the propel study. Hepatology 2010; 52: 360A.

53. Lawitz E, Lalezari JP, Rodriguez-Torres $M$ et al. High rapid virologic response (RVR) with PSI-7977 qd plus PEG-IFN/ RBV in a 28-day phase 2a trial. Hepatology 2010; 52: 706A.

54. Pharmasset Inc. Positive preliminary antiviral data with PSI938 for the treatment of hepatitis C. Press Release 2010; htpp://investor.pharmasset.com/releasedetail.cfm?Relea seID =531337; accessed on 01.12.2010.

55. Brainard DM, Anderson MS, Petry A et al. Safety and antiviral activity of NS5B polymerase inhibitor MK-3281 in treatment-naive genotype $1 \mathrm{a}, 1 \mathrm{~b}$ and $3 \mathrm{HCV}$-infected patients. Hepatology 2009; 50: 1026A.

56. Erhardt A, Deterding K, Benhamou Y et al. Safety, pharmacokinetics and antiviral effect of BILB 1941, a novel hepatitis $C$ virus RNA polymerase inhibitor, after 5 days oral treatment. Antivir Ther 2009; 14: 23-32.
57. Larrey DG, Benhamou Y, Lohse AW et al. BI 207127 is a potent HCV RNA polymerase inhibitor during 5 days monotherapy in patients with chronic hepatitis C. Hepatology 2009; 50: 1044A.

58. Larrey DG, Lohse AW, de Ledinghen V et al. 4 week therapy with the non-nucleoside polymerase inhibitor BI207127 in combination with peginterferon-alfa2a and ribavirin in treatment naive and treatment experienced chronic HCV GT1 patients. J Hepatol 2010; 52: S466.

59. Jacobson IM, Pockros PJ, Lalezari J et al. Virologic response rates following 4 weeks of filibuvir in combination with pegylated interferon alfa-2a and ribavirin in chronically-infected HCV genotype-1 patients. J Hepatol 2010; 52: S465.

60. Cooper C, Lawitz EJ, Ghali P et al. Evaluation of VCH-759 monotherapy in hepatitis C infection. J Hepatol 2009;51: 39-46.

61. Lawitz E, Cooper C, Rodriguez-Torres M et al. Safety, tolerability and antiviral activity of VCH-916, a novel non-nucleoside HCV polymerase inhibitor in patients with chronic HCV genotype-1 infection. J Hepatol 2009; 50: S37.

62. Rodriguez-Torres M, Lawitz E, Conway B et al. Safety and antiviral activity of the HCV non-nucleoside polymerase inhibitor VX-222 in treatment-naive genotype $1 \mathrm{HCV}$-infected patients. J Hepatol 2010; 52: S14.

63. Lawitz E, Rodriguez-Torres M, Rustgi VK et al. Safety and antiviral activity of ANA598 in combination with pegylated interferon alfa-2a plus ribavirin in treatment-naive genotype1 chronic HCV patients. Hepatology 2010; 52: 334A.

64. Rodriguez-Torres M, Lawitz E, Cohen D et al. Treatmentnaive, HCV genotype 1 -infected subjects show significantly greater HCV RNA decreases when treated with 28 days of ABT-333 plus peginterferon and ribavirin compared to peginterferon and ribavirin alone. Hepatology 2009; 50: 5A.

65. Kneteman NM, Howe AY, Gao T et al. HCV796: A selective nonstructural protein $5 \mathrm{~B}$ polymerase inhibitor with potent anti-hepatitis $\mathrm{C}$ virus activity in vitro, in mice with chimeric human livers, and in humans infected with hepatitis C virus. Hepatology 2009; 49: 745-752.

66. Harris J, Bae A, Sun SC et al. Antiviral response and resistance analysis of treatment-naive HCV infected subjects receiving single and multiple doses of GS-9190. Hepatology 2010; 52: 722A.

67. de Bruijne J, van de Wetering de Rooij J, van Vliet AA et al. Phase I study in healthy volunteers and patients with IDX375, a novel non-nucleoside HCV polymerase inhibitor. Hepatology 2010; 52: 1219A.

68. Gao M, Nettles RE, Belema M et al. Chemical genetics strategy identifies an HCV NS5A inhibitor with a potent clinical effect. Nature 2010; 465: 96-100.

69. Pol S, Everson GT, Ghalib R et al. Once-daily NS5A inhibitor (BMS-790052) plus peginterferon-alpha-2a and ribavirin produces high rates of extended rapid virologic response in treatment-naive HCV-genotype 1 subjects: phase 2a trial. J Hepatol 2010; 52: S462.

70. Colonno R, Peng E, Bencsik M et al. Identification and characterization of PPI-461, a potent and selective HCV NS5A inhibitor with activity against all HCV genotypes. J Hepatol 2010; 52: S14.

71. Gane EJ, Foster GR, Cianciara J et al. Antiviral activity, pharmakokinetics, and tolerability of AZD7295, a novel NS5A inhibitor, in a placebo-controlled multiple ascending dose study in HCV genotype 1 and 3 patients. J Hepatol 2010; 52: S464.

72. Nettles R, Wang X, Quadri S et al. BMS-824393 is a potent hepatitis C virus NS5A inhibitor with substantial antiviral activity when given as monotherapy in subjects with chronic G1 HCV infection. Hepatology 2010; 52: 1203A.

73. Witthoeft T, Hueppe D, John C et al. Efficacy and tolerability of peginterferon alfa-2a or alfa- $2 \mathrm{~b}$ plus ribavirin in the daily routine treatment of patients with chronic hepatitis $C$ in Germany: the PRACTICE study. J Viral Hepat 2010; 17: $459-468$. 
74. Gane EJ, Roberts SK, Stedman CA et al. Oral combination therapy with a nucleoside polymerase inhibitor (RG7128) and danoprevir for chronic hepatitis $C$ genotype 1 infection (INFORM-1): a randomised, double-blind, placebo-controlled, dose-escalation trial. Lancet 2010; 376: 1467-1475.

75. Zeuzem S, Buggisch P, Agarwal A et al. Dual, triple, and quadruple combination treatment with a protease inhibitor (GS-9256) and a polymerase inhibitor (GS-9190) alone and in combination with ribavirin (RBV) or PegIFN/RBV for up to 28 days in treatment naive, genotype $1 \mathrm{HCV}$ subjects. Hepatology 2010; 52: 400A.

76. Zeuzem S, Asselah T, Angus PW et al. Strong antiviral activity and safety of IFN-sparing treatment with the protease inhibitor BI 201335, the HCV polymerase inhibitor BI 207127 and ribavirin in patients with chronic hepatitis C. Hepatology 2010; 52: 876A.

77. Lok AS, Gardiner DF, Lawitz E et al. Combination therapy with BMS-790052 and BMS-650032 alone or with PEGIFN/RBV results in undetectable HCV RNA through 12 weeks of therapy in HCV genotype 1 null responders. Hepatology 2010; 52: 877A.

78. Rong L, Dahari H, Ribeiro RM et al. Rapid emergence of protease inhibitor resistance in hepatitis $C$ virus. Sci Transl Med 2010; 2: 30ra32.

79. Flisiak R, Feinman SV, Jablkowski M et al. The cyclophilin inhibitor Debio 025 combined with PEG IFNalpha2a significantly reduces viral load in treatment-naive hepatitis $\mathrm{C}$ patients. Hepatology 2009; 49: 1460-1468.

80. Horban A, Berak H, Kolakowska-Rzadzka A et al. Sustained virological response after 4-week treatment with debio 025 monotherapy or coadministered with PEG-IFN alpha $2 \mathrm{a}$ in HCV genotype 1 and 3 patients. J Hepatol 2010; 52: S294.

81. Coelmont L, Hanoulle X, Chatterji U et al. DEB025 (Alisporivir) inhibits hepatitis $\mathrm{C}$ virus replication by preventing a cyclophilin A induced cis-trans isomerisation in domain II of NS5A. PLoS One 2010; 5: e13687.

82. Hopkins S, Heuman D, Gavis E et al. Safety, plasma pharmakokinetics, and anti-viral activity of SCY-635 in adult patients with chronic hepatitis $\mathrm{C}$ virus infection. J Hepatol 2009; 50: S36.

83. Hopkins S, Mosier S, Harris R et al. Resistance selection following 15 days of monotherapy with SCY-635 a non-immunosuppressive cyclophilin inhibitor with potent antiHCV activity. J Hepatol 2010; 52: S15.

84. Gazak R, Walterova D, Kren V. Silybin and silymarin--new and emerging applications in medicine. Curr Med Chem 2007; 14: 315-338.

85. Ahmed-Belkacem A, Ahnou N, Barbotte L et al. Silibinin and related compounds are direct inhibitors of hepatitis $\mathrm{C}$ virus RNA-dependent RNA polymerase. Gastroenterology 2010; 138: 1112-1122.

86. Wagoner J, Negash A, Kane OJ et al. Multiple effects of silymarin on the hepatitis C virus lifecycle. Hepatology 2010; 51: 1912-1921.

87. Ferenci P, Scherzer TM, Kerschner H et al. Silibinin is a potent antiviral agent in patients with chronic hepatitis $C$ not responding to pegylated interferon/ribavirin therapy. Gastroenterology 2008; 135: 1561-1567.
88. Biermer M, Schlosser B, Fülöp B et al. A short course of high-dose intravenous silibinin as rescue treatment for hepatitis $C$ patients with incomplete virologic response to peginterferon alfa/ribavirin treatment. Hepatology 2010; 52: 798A.

89. Benhamou Y, Afdhal NH, Nelson DR et al. A phase III study of the safety and efficacy of viramidine versus ribavirin in treatment-naive patients with chronic hepatitis C: ViSER1 results. Hepatology 2009; 50: 717-726.

90. Marcellin P, Gish RG, Gitlin N et al. Safety and efficacy of viramidine versus ribavirin in ViSER2: randomized, doubleblind study in therapy-naive hepatitis $C$ patients. J Hepatol 2010; 52: 32-38.

91. Poordad F, Lawitz E, Shiffman ML et al. Virologic response rates of weight-based taribavirin versus ribavirin in treatment-naive patients with genotype 1 chronic hepatitis C. Hepatology 2010; 52: 1208-1215.

92. Nelson DR, Benhamou Y, Chuang WL et al. Albinterferon Alfa-2b was not inferior to pegylated interferon-alpha in a randomized trial of patients with chronic hepatitis $\mathrm{C}$ virus genotype 2 or 3. Gastroenterology 2010; 139: 1267-1276.

93. Zeuzem S, Sulkowski MS, Lawitz EJ et al. Albinterferon Alfa-2b was not inferior to pegylated interferon-alpha in a randomized trial of patients with chronic hepatitis $C$ virus genotype 1. Gastroenterology 2010; 139: 1257-1266.

94. Long WA, Takov D, Tchernev K et al. Q2week controlledrelease-interferon-alpha $2 \mathrm{~b}+$ ribavirin reduces flu-like symptoms $>50 \%$ and provides equivalent efficacy in comparison to weekly pegylated-interferon-alpha2b+ribavirin in treatment-naive-genotype-1-chronic-hepatitis C: results from EMPOWER, a randomized-open-label-12-week-comparison in 133 patients. J Hepatol 2010; 52: S467-S467.

95. Bacon BR, Shiffman ML, Mendes F et al. Retreating chronic hepatitis $C$ with daily interferon alfacon-1/ribavirin after nonresponse to pegylated interferon/ribavirin: DIRECT results. Hepatology 2009; 49: 1838-1846.

96. Muir AJ, Shiffman ML, Zaman A et al. Phase 1b study of pegylated interferon lambda 1 with or without ribavirin in patients with chronic genotype 1 hepatitis $\mathrm{C}$ virus infection. Hepatology 2010; 52: 822-832.

97. Seden K, Back D, Khoo S. New directly acting antivirals for hepatitis C: potential for interaction with antiretrovirals. J Antimicrob Chemother 2010; 65: 1079-1085.

Received: January 15, 2011 / Accepted: January 20, 2011

Address for correspondence:

Christoph Sarrazin, MD

Medizinische Klinik 1

Klinikum der J.W. Goethe-Universität

Theodor-Stern-Kai 7

60590 Frankfurt am Main

Germany

Phone: +496963015122; Fax: +4969630183112

Email: sarrazin@em.uni-frankfurt.de 